\title{
Formation of nascent char structure during the fast pyrolysis of mallee wood and low-rank coals
}

\section{Lei Zhang ${ }^{1}$, Tingting $\mathrm{Li}^{1}$, Dimple Quyn ${ }^{1}$, Li Dong ${ }^{1}$, Penghua Qiu ${ }^{1,2}$,}

$$
\text { Chun-Zhu Li }{ }^{1, *}
$$

${ }^{1}$ Fuels and Energy Technology Institute, Curtin University of Technology, GPO Box U1987, Perth,

WA 6845, Australia

$10{ }^{2}$ School of Energy Science and Engineering, Harbin Institute of Technology, 92 West Dazhi Street, Harbin, Heilongiiang 150001, People's Republic of China

* Corresponding author:

E-mail address: chun-zhu.li@ curtin.edu.au (Chun-Zhu Li)

Phone: +61 892661131

Fax: $\quad+61892661138$

December 2014 
The structural evolution of nascent chars during the fast pyrolysis of a wood and two lowrank coals was investigated in this study. Western Australian Collie sub-bituminous coal, Victorian Loy Yang brown coal and Western Australian mallee wood were pyrolysed in a

30 wire-mesh reactor that is capable of providing rapid heating rates (up to $5000 \mathrm{~K} \mathrm{~s}^{-1}$ ) and accurate holding time (in increments of $10 \mathrm{~ms}$ ) at peak temperature. FT-Raman spectroscopy was used to characterise the key structural features of raw fuels and nascent chars. The combined use of a wire-mesh reactor and a FT-Raman spectroscopy has given insights into the structural transformation from coal/biomass to nascent chars. There were insignificant changes in the aromatic ring systems of two coals during the initial fast heating from room temperature to $600{ }^{\circ} \mathrm{C}$. During holding at $600{ }^{\circ} \mathrm{C}$, the changes that occurred in ring systems for the three fuels were different. Mallee wood and Loy Yang coal underwent more changes than Collie coal. In addition, mallee wood had ring condensation during holding at $600{ }^{\circ} \mathrm{C}$ up to 30s. However, little growth in large aromatic rings of two coals was observed during holding at $600{ }^{\circ} \mathrm{C}$ up to $50 \mathrm{~s}$.

Keywords: Collie coal; Loy Yang coal; Mallee wood; Fast pyrolysis; Char structure. 


\section{Introduction}

Gasification converts solid fuels into clean syngas and is the core of many low-emission energy technologies [1]. As the char gasification rate controls the overall gasification rate [2], effort has been made to evaluate the possible factors influencing the char reactivity [2-4]. Among many important factors, the structural evolution of char has been shown [4-17] to be a significant aspect that affect the changes in coal [4-7] or biomass [8-11] char reactivity and the behaviour of catalysts [13-15].

The formation of char is complicated. Several structural changes could take place in the initial transition from coal to char with the concurrent release of volatiles. For example, while

55 large aromatic and heteroaromatic ring systems (e.g. with more than 4 or 5 fused benzene rings) dominate in the char structure, they exist in low-rank coals at relatively low concentrations $[18,19]$. The long-chain aliphatics in a low-rank coal are almost absent in its chars formed at $600{ }^{\circ} \mathrm{C}$ and higher [20]. Many O-containing functional groups (e.g. carboxylic acids) in abundance in a low-rank coal will also be decomposed and released as gases [20] during the initial process to form a char. Some recent studies in our group focused on the changes in relatively "old" char structure during pyrolysis/gasification in fluidised bed for biomass [8-11] and low-rank coal [12-14, 16-17]. However, there is a lack of experimental data on the detailed structural features of the newly formed (nascent) char. The time scale for the conversion of coal to char is very short: the evolution of tar is completed as soon as the coal particles are heated up to $600{ }^{\circ} \mathrm{C}$ at $1000 \mathrm{~K} \mathrm{~s}^{-1}$ [21, 22]. Very few reactors are capable of providing a well-controlled heating rate and a high resolution of holding time. A wire-mesh reactor [21-23] is one such reactor due to its well-known ability to control linear 
heating rate over a wide range from $0.1-5000 \mathrm{~K} \mathrm{~s}^{-1}$ and to provide holding time in increments of $10 \mathrm{~ms}$.

Volatile-char interactions can drastically change the pathway of char structural evolution [3]. A wire-mesh reactor has the special advantage in that volatiles, once released from the parent pyrolysing coal/char particles, are swept away and will have minimal inter-particle interactions with the char particles. Therefore, the wire-mesh reactor provides a means to investigate the structural formation of nascent char in the absence of the influence of volatilechar interactions.

A quantitative method to describe the char chemical structural features is a necessity to trace the development of char structure during pyrolysis. Our recent studies have shown that FTRaman spectroscopy combined with spectral deconvolution is a powerful technique to semiquantify the structural features of chars produced from the pyrolysis/gasification of biomass [8-11] and coal [12-14, 16-17]. The FT-Raman spectra of coal/char over the range between 800 and $1800 \mathrm{~cm}^{-1}$ were deconvoluted into 10 bands [12]. The overall changes in the aromatic structures, oxygen-containing functional groups and cross-links can be investigated.

The purpose of this study is to characterise the chemical structural features of nascent chars during the pyrolysis of Loy Yang brown coal, Collie sub-bituminous coal and Western Australian mallee wood. By using FT-Raman spectroscopy on the analyse of the chars prepared in a wire-mesh reactor, our results reveal some details about the structural information of nascent char, especially the changes in char structure during the initial release of tar at $<600{ }^{\circ} \mathrm{C}$ with $1000 \mathrm{~K} \mathrm{~s}^{-1}$ heating rate and the changes after further holding at $600{ }^{\circ} \mathrm{C}$ with the holding time up to $50 \mathrm{~s}$. All experiments were carried out at atmospheric pressure. 


\section{Experimental}

\subsection{Samples preparation}

Collie sub-bituminous coal from Western Australia, Loy Yang brown coal from Victoria and mallee wood from Western Australia were used. The preparation procedure of Collie coal was the same as that for Loy Yang coal [24]. Briefly, "as mined" coal with particle sizes mainly around 10-20 cm was obtained and dried at ambient temperature. The air-dried raw coal was pulverised and screened to the particle size range of 106-150 $\mu \mathrm{m}$. The preparation of mallee wood was described elsewhere [25], the wood with particle size range of 180-400 $\mu \mathrm{m}$ was chosen. As the mallee wood particles were long and thin, the particles were cut into circular-like pieces by hand to obtain a better particle distribution on the sample holder. The proximate and ultimate analyses of the three fuels are shown in Table 1.

\subsection{Pyrolysis}

The pyrolysis of the three fuels was carried out using a wire-mesh reactor at a fast heating 110 rate of $1000 \mathrm{~K} \mathrm{~s}^{-1}$. The details of the wire-mesh reactor and the operation procedure can be found elsewhere $[23,24]$. Briefly, a small amount of coal or biomass (typically less than 10 mg) was sandwiched between two layers of mesh made from grade 316 stainless steel with an aperture of $45 \mu \mathrm{m}$. The mesh was stretched between two electrodes for heating samples with an alternating current. During the heating of the particles, a stream of ultra-high purity helium

115 passed through the mesh vertically at the flow rate of $0.1 \mathrm{~m} \mathrm{~s}^{-1}$ (measured under ambient conditions). With the contribution of the cooling carrier gas (helium), volatiles were 
quenched and removed out of char immediately after evolution from the samples to minimise the volatile-char interactions.

The temperature of sample was detected by two pairs of chromel/alumel alloy wires. One pair was inserted at the centre of the area containing the coal particles and the other was inserted at around $1 \mathrm{~mm}$ from the edge. The average of these two temperatures was used as a feedback for controlling the mesh temperature with a PID control system. The holding time can be preset and controlled at $10 \mathrm{~ms}$ increments. The empty stainless steel sample holder was preheated to the target temperatures to prevent further weight loss in pyrolysis experiments. A balance with precision of $0.01 \mathrm{mg}$ was used for all weight measurement. Char yield was determined by the difference in the weight of the loaded sample holder before and after an experiment. In addition, all the char in a single experiment was collected and directly mixed with $\mathrm{KBr}$ for Raman analysis.

\subsection{Raman spectroscopy for char characterisation}

The FT-Raman spectra of fuels and chars were acquired by using a Perkin-Elmer Spectrum GX FT-Raman spectrometer. The fuel/char sample was mixed, diluted and ground with spectroscopic grade potassium bromide (KBr) that was used as a heat dissipating agent [12]. The selection of coal/char concentration in $\mathrm{KBr}$ will be discussed in Section 3.3.1. The Raman spectra in the range between 800 and $1800 \mathrm{~cm}^{-1}$ were deconvoluted into 10 Gaussian bands. The assignment of 10 bands was summarised in our previous study [12]. An example of Raman spectrum with 10 bands deconvolution is shown in Fig. 1. The total Raman area and Raman band ratios were used to characterise the fuel/char structural features in this study. 


\section{Results and discussion}

\subsection{Char yields of three fuels during initial pyrolysis}

145 Fig. 2 shows the changes in char yield as a function of holding time during the pyrolysis of Loy Yang brown coal, Collie sub-bituminous coal and Western Australia mallee wood at $600{ }^{\circ} \mathrm{C}$ with a heating rate of $1000 \mathrm{~K} \mathrm{~s}^{-1}$. All the char yields were on dry basis. As shown in Fig. 2, the char yields of all three fuels had fast declines within $1 \mathrm{~s}$ and then only slight changes in weight loss were observed during further holding. The differences in char yields between three fuels were quite large at $600{ }^{\circ} \mathrm{C}$; these differences were firstly observed with 0 $\mathrm{s}$ holding at $600{ }^{\circ} \mathrm{C}$. The $0 \mathrm{~s}$ holding means the char only underwent the heating from room temperature to $600{ }^{\circ} \mathrm{C}$ at $1000 \mathrm{~K} \mathrm{~s}^{-1}$ and then naturally cooled down to the room temperature without any residence at peak temperature.

\subsection{Raman spectra of raw fuels and nascent chars}

Fig. 3 shows the Raman spectra of three fuels and their nascent chars with $0 \mathrm{~s}$ and $10 \mathrm{~s}$ holding. Mallee wood had a distinctively different spectrum from other two fuels/chars. It is indicated that the structure of mallee wood that is different from the coals/chars could not be deconvoluted by the same method. However, after fast heating to $600{ }^{\circ} \mathrm{C}$, the Raman spectrum of mallee wood char showed a similar shape to those of coal chars.

The changes in the Raman spectra of three fuels mainly occurred in three areas. Firstly, the Raman intensity decreased at wavenumbers between $1300 \mathrm{~cm}^{-1}$ (D band) and $1590 \mathrm{~cm}^{-1}$ (G band). The overlap between $\mathrm{D}$ band and $\mathrm{G}$ band is normally divided into 3 bands ( $\mathrm{Gr}, \mathrm{Vl}$ and 
Vr) which represent the highly disordered amorphous carbon structure and small aromatic rings with 3-5 rings. Secondly, the D band at $1300 \mathrm{~cm}^{-1}$, which represents large aromatic rings with $\geq 6$ rings, showed a gradual growth during pyrolysis. Thirdly, the band at $\sim 960$ $\mathrm{cm}^{-1}$, which is called the $\mathrm{R}$ band, decreased significantly during the initial pyrolysis of all three fuels. It mainly represents the alkane structures, cyclic alkane structures or $\mathrm{C}-\mathrm{H}$ on aromatic rings. In order to analyse the changes in char structural features during fast pyrolysis, the Raman spectra were deconvoluted into 10 bands, which are shown in Fig. 1. The changes in total Raman area, $(\mathrm{Gr}+\mathrm{Vl}+\mathrm{Vr}) / \mathrm{D}, \mathrm{S}$ band and $\mathrm{R}$ band will be discussed in the following sections.

\subsection{Changes in char structure during the initial pyrolysis}

\subsubsection{Total Raman area as a function of coal/char concentration in coal/char-KBr mixture}

Fig. 4 shows the total Raman areas between 800 and $1800 \mathrm{~cm}^{-1}$ as a function of coal/char concentration in the coal/char- $\mathrm{KBr}$ mixture of three fuels. It is clear that, for all char samples, with the increase in coal/char concentration in the mixture, the Raman intensity has an initial rapid increase and gradually reaches a plateau. Our previous work indicated that the char that had higher light absorptivity would cause the total Raman area to reach the plateau much quicker and at a much lower concentration [12]. As discussed in Section 3.2, the Raman spectrum of raw mallee wood was different from that of coals and chars that cannot be deconvoluted by the 10 bands method. Therefore, the total Raman area of the two raw coals and the nascent chars of the three fuels were studied in this section. As shown in Fig. 4(a), the 
indicated that Loy Yang coal is not rich in structures with high light absorptivity such as large aromatic ring systems. Additionally, the higher total Raman area of Loy Yang coal than that of Collie coal showed the greater amounts of O-containing functional groups in the Loy Yang coal. Although the total Raman area of Loy Yang coal was much higher than that of Collie coal, the total Raman area of the chars produced at $600{ }^{\circ} \mathrm{C}$ with $0 \mathrm{~s}$ holding [Fig. 4(b)] were close for the two coals. The reason for this rapid decrease in total Raman area of Loy Yang coal will be discussed in following sections. For the mallee wood char produced at $600{ }^{\circ} \mathrm{C}$ with 0 s holding [Fig. 4(b)], it reached a plateau at $\sim 0.8 \%$. However, for the mallee wood chars produced at $600{ }^{\circ} \mathrm{C}$ with $0.1 \mathrm{~s}$ holding, the total Raman area reached a plateau at concentrations $<0.25 \%$. Fig. $4(\mathrm{~b})$ also showed that a concentration of $0.25 \%$ was high enough for the total Raman area of the chars from the two coals to reach a plateau.

\subsubsection{Changes in total Raman area during initial pyrolysis}

205 The total Raman areas between 800 and $1800 \mathrm{~cm}^{-1}$ as a function of holding time and temperature are shown in Fig. 5. The data at $100 \%$ char yield represent the total Raman areas of two raw coals, while all the other points refer to the total Raman areas of the chars produced from the pyrolysis of three fuels at $600{ }^{\circ} \mathrm{C}$. The starting point of mallee wood char in Fig. 5 was the char produced at $600{ }^{\circ} \mathrm{C}$ with $0 \mathrm{~s}$ holding time. The sample concentrations 210 in the sample-KBr mixtures for Loy Yang raw coal and Collie raw coal were chosen as 5\% and $1 \%$. As was mentioned above, the total Raman area of Loy Yang raw coal had not reached the plateau value when the concentration was 5\%. Therefore, the actual plateau total Raman area of Loy Yang coal should be higher than the value shown in Fig. 5. The concentration of all other samples was selected where the total Raman area of nascent chars 215 already reached a plateau (Fig. 4). 
Total Raman area is mainly affected by the oxygen containing functional groups and the aromatic ring systems. The former would have a resonance effect with the aromatic ring to which it connects and increase the Raman scattering intensity, while the latter would enhance the light absorptivity and weaken the Raman intensity. As shown in Fig. 5, the total Raman area of Loy Yang coal decreased significantly during initial heating from raw coal at the char yield of $100 \%$ to nascent char $\left(600{ }^{\circ} \mathrm{C}\right.$ with $0 \mathrm{~s}$ holding $)$ at the char yield of $55 \%$, while the total Raman area changed little during holding at $600{ }^{\circ} \mathrm{C}$. As for Collie coal, negligible changes in total Raman area occurred during heating from raw coal to nascent char $\left(600{ }^{\circ} \mathrm{C}\right.$ with $0 \mathrm{~s}$ holding), while a rapid decrease took place in the total Raman area of Collie coal when the nascent char was holding at $600{ }^{\circ} \mathrm{C}$. Similarly, mallee wood also showed a rapid decline in total Raman area during holding at $600{ }^{\circ} \mathrm{C}$. For all of the decreases in the total Raman area of the three fuels, it might be attributed to the loss of O-containing functional groups and/or the condensation of aromatics, which will be discussed further below.

\subsubsection{Changes in ring systems during initial pyrolysis}

Fig. 6 shows the changes in the ratio of $I_{(G r+V l+V r)}$ to $I_{D}$ that refers to the ratio of small ( 3 to 5 rings) to large aromatic rings ( $\geq 6$ rings) during the initial pyrolysis of the two coals from 235 room temperature to $600{ }^{\circ} \mathrm{C}$ and the further pyrolysis of the three fuels during holding at $600{ }^{\circ} \mathrm{C}$.

For Loy Yang coal, char yield decreased from 100 to $~ 55 \%$ during the heating from room temperature to $600{ }^{\circ} \mathrm{C}$ (with $0 \mathrm{~s}$ holding), while negligible change was observed in the ratio 240 between small and large rings. During the initial pyrolysis of Collie coal, the char yield 
dropped from 100 to $\sim 75 \%$ with only very slight increase in the ratio of small to large rings when heating from room temperature to $600{ }^{\circ} \mathrm{C}$. It is indicated that little changes happen in aromatic ring systems during the initial pyrolysis for two coals. Additionally, as shown in Fig. 2, volatiles from two coals were rapidly released during initial heating from room temperature to $600{ }^{\circ} \mathrm{C}$. During this explosive release of volatiles, most tar molecules that were rich in aromatic rings were also released [21, 22]. The source of these aromatic rings in tar might be from the direct detachment of original aromatic rings from the parent fuels, or from the newly formed aromatics via reactions such as dehydrogenation of hydroaromatics. Therefore, the negligible changes in Collie coal and Loy Yang coal on heating up suggested that the formation and growth (if any) of aromatic rings during the release of tar would have very limited effects on aromatic ring systems in two coals. In other words, the tar precursor might be mainly formed through the breakage of aliphatic structures and released with little effect on the original ring systems in the two coals.

255 Besides the tar evolution, there are other factors that may affect the formation of ring systems in char. Firstly, the aromatic rings in volatiles may recombine on the char matrix to form more condensed aromatic rings. Secondly, the loss of substitutional groups during the initial pyrolysis may create free sites on aromatic rings, which combine to form larger ring systems or cross-links. However, as discussed above, insignificant changes in ring systems were 260 observed for the two coals. It may be due to two reasons. Firstly, during fast pyrolysis, the volatile precursors largely build up the pressure within the pyrolysing coal particles and release explosively [22]. Thus, the volatiles only have a very short residence time to react with char. Secondly, the presence of long chain aliphatic or other bulky substitution groups in low-rank coals may create steric hindrance for the recombination of free sites on char [27], which caused the free sites well detached and prevent the formation of larger rings and cross- 
links. In any case, the structures in coal were not reactive enough to form additional aromatic structures during the very short period of heating up.

During holding at $600{ }^{\circ} \mathrm{C}$, the three fuels showed different extents of changes in ring systems. With the decrease in char yield from $\sim 75$ to $\sim 65 \%$, Collie coal showed insignificant changes in ring systems during holding up to $50 \mathrm{~s}$. With the decrease in char yield from $\sim 55$ to $\sim 45 \%$, Loy Yang coal showed significant decreases in the ratio of $\mathrm{I}_{(\mathrm{Gr}+\mathrm{Vl}+\mathrm{Vr})} / \mathrm{I}_{\mathrm{D}}$ within the holding time of $50 \mathrm{~s}$. It could be attributed to the selective loss of small aromatic ring systems or the condensation of ring systems. However, the changes in the total Raman area as a function of char yield shown in Fig. 5 revealed that there was no significant change during holding at $600{ }^{\circ} \mathrm{C}$ for Loy Yang coal. As ring condensation would greatly increase the light absorptivity of char and decrease the total Raman area, the decrease in $\mathrm{I}_{(\mathrm{Gr}+\mathrm{Vl}+\mathrm{Vr})} / \mathrm{I}_{\mathrm{D}}$ with little change in total Raman area should be mainly due to the selective release of small ring systems, although the ring growth cannot be ruled out. Mallee wood also showed a decrease in ratio between small and large rings during holding at $600{ }^{\circ} \mathrm{C}$ up to $30 \mathrm{~s}$. However, it decreased gradually before the char yield reached $9 \%$ and then decreased significantly after the char yield reduced to $<9 \%$. At the char yield $>9 \%$, with the decrease in $\mathrm{I}_{(\mathrm{Gr}+\mathrm{Vl}+\mathrm{Vr})} / \mathrm{I}_{\mathrm{D}}$, the total Raman area changed little with decrease in char yield (Fig. 5), which was mainly due to the selective release of small ring systems. By contrast, after further holding at $600{ }^{\circ} \mathrm{C}$, the char 285 yield changed very little while the ratio decreased sharply. It is mainly due to ring condensation that results in the conversion of small to large ring systems with the release of very light gases: particularly $\mathrm{H}_{2}$. The decline in the total Raman area of mallee wood, shown in Fig. 5, might be mainly due to the ring condensation and the loss of O-containing functional groups. 
Comparing the differences in the formation of ring systems in three fuels during holding at $600{ }^{\circ} \mathrm{C}$ in Fig. 6, it is clear that the three fuels have different ratios of small to large rings at the beginning of holding $\left(\mathrm{I}_{(\mathrm{Gr}+\mathrm{Vl}+\mathrm{Vr})}\right)_{\mathrm{D}}$ of mallee wood at $\sim 23 \%>$ Loy yang coal at $\sim 55 \%>$ Collie coal at $\sim 75 \%$ ). Subsequently, it is easier to have thermal decomposition or condensation of ring systems taken place for the brown coal and wood than that for the subbituminous coal. It is suspected that the smaller ring systems in char have fewer cross-links than the bigger ones [28]. Therefore, the thermal breakdown would be easier in the brown coal and wood that are richer in smaller rings than in sub-bituminous coal at the same temperature. It is supported by the greater release of volatiles for brown coal and wood than sub-bituminous coal shown in Fig. 2.

As was discussed in Section 3.3.2, the decrease in the total Raman area of the three fuels shown in Fig. 5 might be attributed to two reasons: the loss of O-containing functional groups and/or the condensation of aromatics. On the basis of the discussion about the ring systems above, for two coals, with the total Raman area decreasing (Fig 5), insignificant changes in ring systems were observed (Fig. 6). It reveals that the reduction in Raman intensity is mainly due to the loss of O-containing functional groups. Correlating the changes in the total Raman area (Fig. 5) with the changes in the ratio of small to large rings (Fig. 6), the two coals showed different reaction pathway from mallee wood. As for the two coals, the total Raman area significantly decreased when the ratio of small to large rings changed little (Loy Yang coal at char yield from 100 to $\sim 55 \%$; Collie coal at char yield from $\sim 75$ to $\sim 65 \%$ ). However, for mallee wood, the total Raman area decreased when the aromatic ring systems correspondingly changed (mallee wood at char yield $<9 \%$ ). It is suggested that the reactions for the release of O-containing functional groups and those for the changes in ring size 315 distribution happens independently for the two coals but simultaneously for mallee wood. 


\subsubsection{The changes in cross-links during initial pyrolysis}

The ratios of $\mathrm{S}$ band area to the total Raman area as a function of holding time and temperature are shown in Fig. 7. It represents cross-links in the carbonaceous structure. 320 Although there were large amounts of volatiles released, Loy Yang coal and mallee wood showed little increase in the relative intensity of $S$ band during the initial stage of pyrolysis. The reason for this might be the same as the reason for the insignificant changes in ring systems during initial pyrolysis shown in Section 3.3.3. Briefly, the residence time of volatile precursors in the nascent char particle was too short for significant secondary reactions involving volatile precursors to take place. Furthermore, the possible free radical sites generated in char from the breakage of the bulky substitution groups in biomass or Loy Yang coal caused the free sites must have been well separated for them to recombine. Both reasons enhanced the chance for the free sites to be stabilised rather than to form cross-links. Collie coal showed slightly higher cross-links than the other fuels during initial heating. It might be attributed to the lower amount of volatiles released during the initial pyrolysis and the more cracking of structures in char for enhanced formation of cross-links.

During holding at $600{ }^{\circ} \mathrm{C}$, a rapid increase in cross-links was observed for all three fuels. It implies that the significant formation of cross-links follows the thermal decomposition of 335 bulky substitutions.

\subsubsection{The changes in $R$ band as a function of char yield}

The ratios of the $\mathrm{R}$ band area to the total Raman area as a function of char yield are shown in

Fig. 8. The R band represents the presence of alkane structures, cyclic alkane structures (e.g. 
hydro-aromatics) or the $\mathrm{C}-\mathrm{H}$ bond on aromatic rings. Given the highly reactive nature of these aliphatic and cyclic aliphatic structures, the changes in the relative $\mathrm{R}$ band intensity provide another dimension of the structural transformation from fuel to nascent char.

345 Again, three fuels show very different behaviours. For the Collie sub-bituminous coal, the initial heating up to $600{ }^{\circ} \mathrm{C}$ caused little changes in the relative intensity of the $\mathrm{R}$ band, indicating that the release of volatiles was quick and that the volatiles had very similar structures (in terms of $\mathrm{R}$ band) to the remaining nascent char. On holding at $600{ }^{\circ} \mathrm{C}$, the hydroaromatics would dehydrogenate and some aliphatic long chain structures would be broken off.

The data in Fig. 8 indicate that significant changes in the R band intensity took place during the initial heating/devolatilisation of the Loy Yang brown coal. Clearly, the volatiles released had different structures from the remaining char. Certainly, much of the long-chain aliphatics would be released during the initial release of volatiles due to the high heating rate. On holding, the relative $\mathrm{R}$ band intensity decreased rapidly, most probably due to the combined effects of dealkylation and dehydrogenation of hydroaromatics structures.

The nascent char from wood also underwent drastic changes in the relative intensity of the $\mathrm{R}$ band. In addition to dealkylation and dehydrogenation reactions mentioned above for the brown coal and sub-bituminous coal, dehydration reactions (e.g. the dehydration of sugartype structures) followed by the growth of aromatic rings would have also contributed to the changes in the R band intensity. 


\section{Conclusions}

This study was an investigation of the reactions taking place during the transition from coal/biomass to char, in particular the formation of structural features of nascent char.

1. Mallee wood has different reaction pathway from two coals during the formation of nascent char structure. Mallee wood shows a significantly different carbon structure to that of coals (Raman spectroscopy). However, it changed significantly during initial pyrolysis and approached the carbon structure of coal chars.

375

2. The release of O-containing functional groups (in terms of total Raman area) occurred independently with the changes in ring size distribution for the two coals but simultaneously for mallee wood.

3 All three fuels showed selective release of small aromatic ring systems during holding at $600{ }^{\circ} \mathrm{C}$. However, only mallee wood showed ring condensation during holding at $600{ }^{\circ} \mathrm{C}$ (char yield $<9 \%$ ).

4. Loy Yang brown coal and Collie sub-bituminous coal show only slight changes in ring systems and cross-linking structures during the initial heating process when there were large amounts of volatiles released. Since tar molecules are primarily released during the initial heating process, the insignificant changes in ring systems of two coals indicated that the formation and release of ring systems in tar mainly occurred through the breakage of aliphatic structures and released with little effect on the original ring systems in the two coals. 
5 During holding at $600{ }^{\circ} \mathrm{C}$, when the release of volatiles was low, different changes in ring systems occurred for the three fuels. The lower-rank fuels that were rich in small aromatic rings seemed easier to have decomposition or condensation of ring systems taken place than the higher-rank fuel.

6 The $\mathrm{R}$ band represents alkane structures, cyclic alkane structures or $\mathrm{C}-\mathrm{H}$ on aromatic rings, which are very reactive; the $\mathrm{R}$ band of three fuels decreased very fast during holding at $600{ }^{\circ} \mathrm{C}$ up to $50 \mathrm{~s}$.

\section{Acknowledgements}

The authors gratefully acknowledge the financial support of this study from the Australian Research Council (DP110105514), the Commonwealth of Australia under the Australia-china Science and Research Fund and WA Department of Mines and Petroleum. The authors also gratefully thank the Muja power plant for providing the Collie coal sample.

\section{References}

[1] Li C-Z. Special issue-gasification: a route to clean energy. Process Safety and Environmental Protection 2006;84:407-8.

410 [2] Miura K, Hashimoto K, Silveston PL. Factors affecting the reactivity of coal chars during gasification, and indices representing reactivity. Fuel 1989;68:1461-75.

[3] Li C-Z. Some recent advances in the understanding of pyrolysis and gasification behaviour of Victorian brown coal. Fuel 2007;86:1664-83.

[4] Van Heek KH, Mühlen HJ. Aspects of coal properties and constitution important for gasification. Fuel 1985;64:1405-14. 
[5] Davis KA, Hurt RH, Yang NYC, Headley TJ. Evolution of char chemistry, crystallinity, and ultrafine structure during pulverized-coal combustion. Combustion and Flame 1995;100:3140.

[6] Senneca O, Salatino P, Masi S. Microstructural changes and loss of gasification reactivity of 420 chars upon heat treatment. Fuel 1998;77:1483-93.

[7] Chan M-L, Jones JM, Pourkashanian M, Williams A. The oxidative reactivity of coal chars in relation to their structure. Fuel 1999;78:1539-52.

[8] Keown DM, Hayashi J-I, Li C-Z. Drastic changes in biomass char structure and reactivity upon contact with steam. Fuel 2008;87:1127-32.

425 [9] Keown DM, Li X, Hayashi J-I, Li C-Z. Characterization of the structural features of char from the pyrolysis of cane trash using fourier transform- Raman spectroscopy. Energy \& Fuels 2007;21:1816-21.

[10] Asadullah M, Zhang S, Min Z, Yimsiri P, Li C-Z. Effects of biomass char structure on its gasification reactivity. Bioresource Technology 2010;101:7935-43.

430 [11] Zhang S, Min Z, Tay H-L, Wang Y, Dong L, Li C-Z. Changes in char structure during the gasification of mallee wood: effects of particle size and steam supply. Energy \& Fuels 2012;26:193-8.

[12] Li X, Hayashi J-I, Li C-Z. FT-Raman spectroscopic study of the evolution of char structure during the pyrolysis of a Victorian brown coal. Fuel 2006;85:1700-7.

435 [13] Li X, Li C-Z. Volatilisation and catalytic effects of alkali and alkaline earth metallic species during the pyrolysis and gasification of Victorian brown coal. Part VIII. Catalysis and changes in char structure during gasification in steam. Fuel 2006;85:1518-25.

[14] Li X, Hayashi J-I, Li C-Z. Volatilisation and catalytic effects of alkali and alkaline earth metallic species during the pyrolysis and gasification of Victorian brown coal. Part VII. Raman spectroscopic study on the changes in char structure during the catalytic gasification in air. Fuel 2006;85:1509-17.

[15] Wu H, Hayashi J-I, Chiba T, Takarada T, Li C-Z. Volatilisation and catalytic effects of alkali and alkaline earth metallic species during the pyrolysis and gasification of Victorian brown 
coal. Part V. Combined effects of Na concentration and char structure on char reactivity. Fuel 2004;83:23-30.

[16] Tay H-L, Li C-Z. Changes in char reactivity and structure during the gasification of a Victorian brown coal: Comparison between gasification in $\mathrm{O}_{2}$ and $\mathrm{CO}_{2}$. Fuel Processing Technology 2010;91:800-4.

[17] Guo X, Tay H-L, Zhang S, Li C-Z. Changes in char structure during the gasification of a Victorian brown coal in steam and oxygen at $800{ }^{\circ} \mathrm{C}$. Energy \& Fuels 2008;22:4034-8.

[18] Kashimura N, Hayashi J-I, Li C-Z, Sathe C, Chiba T. Evidence of poly-condensed aromatic rings in a Victorian brown coal. Fuel 2004;83:97-107.

[19] Hayashi J-I, Li C-Z. Structure and properties of Victorian brown coal. In: Li C-Z, editor. Advances in the science of Victoria brown coal. Oxford: Elsevier; 2004. P. 11-77 (Chapter 2).

[20] Hayashi J-I, Miura K. Pyrolysis of Victorian brown coal. In: Li C-Z, editor. Advanced in the science of Victorian brown coal. Oxford: Elsevier; 2004. P. 134-217(Chapter 4).

[21] Sathe C, Hayashi J-I, Li C-Z. Release of volatiles from the pyrolysis of a Victorian lignite at elevated pressures. Fuel 2002;81:1171-8.

[22] Jamil K, Hayashi J-I, Li C-Z. Pyrolysis of a Victorian brown coal and gasification of nascent char in $\mathrm{CO}_{2}$ atmosphere in a wire-mesh reactor. Fuel 2004;83:833-43.

[23] Gibbins J.R., King R.A.V., Wood R.J., Kandiyoti R.. Variable-heating-rate wire-mesh pyrolysis apparatus. Review of Scientific Instruments 1989;60:1129-39.

[24] Sathe C, Pang Y, Li C-Z. Effect of heating rate and ion-exchangeable cations on the pyrolysis yields from a Victorian brown coal. Energy \& Fuels 1999;13:748-55.

465 [25] Asadullah M, Zhang S, Li C-Z. Evaluation of structural features of chars from pyrolysis of biomass of different particle sizes. Fuel Processing Technology 2010; 91:877-81.

[26] Li T, Zhang L, Dong L, Li C-Z. Effects of gasification atmosphere and temperature on char structural evolution during the gasification of Collie sub-bituminous coal. Fuel 2014;117:1190-5.

470 [27] Sathe C. Fates and roles of alkali and alkaline earth metallic species during the pyrolysis of low-rank coals. PhD Thesis, Monash University, 2001:189-98. 
[28] Li C-Z, Madrali E.S, Wu F, Xu B, Cai H-Y, Güell AJ et al. Comparison of thermal breakdown in coal pyrolysis and liquefaction. Fuel 1994;73:851-65. 
Table 1 Properties of three fuels $[10,16,26]$

\begin{tabular}{cccccccc}
\hline & \multicolumn{3}{c}{ Proximate analysis (wt\%) } & \multicolumn{5}{c}{ Ultimate analysis (wt\%) } \\
\cline { 2 - 8 } & Ash $^{\mathrm{a}}$ & Volatile matter $^{\mathrm{b}}$ & $\mathrm{C}^{\mathrm{b}}$ & $\mathrm{H}^{\mathrm{b}}$ & $\mathrm{N}^{\mathrm{b}}$ & $\mathrm{S}^{\mathrm{b}}$ & $\mathrm{O}^{\mathrm{b} . \mathrm{c}}$ \\
\hline Mallee wood & 0.9 & 81.6 & 48.2 & 6.1 & 0.2 & 0.0 & 45.5 \\
Loy Yang coal & 1.1 & 52.2 & 70.4 & 5.4 & 0.6 & 0.3 & 23.2 \\
Collie coal & 5.7 & 38.8 & 75.7 & 4.5 & 1.4 & 0.5 & 17.9 \\
\hline
\end{tabular}

(a, dry basis; $b$, dry and ash-free basis; $c$, by difference) 


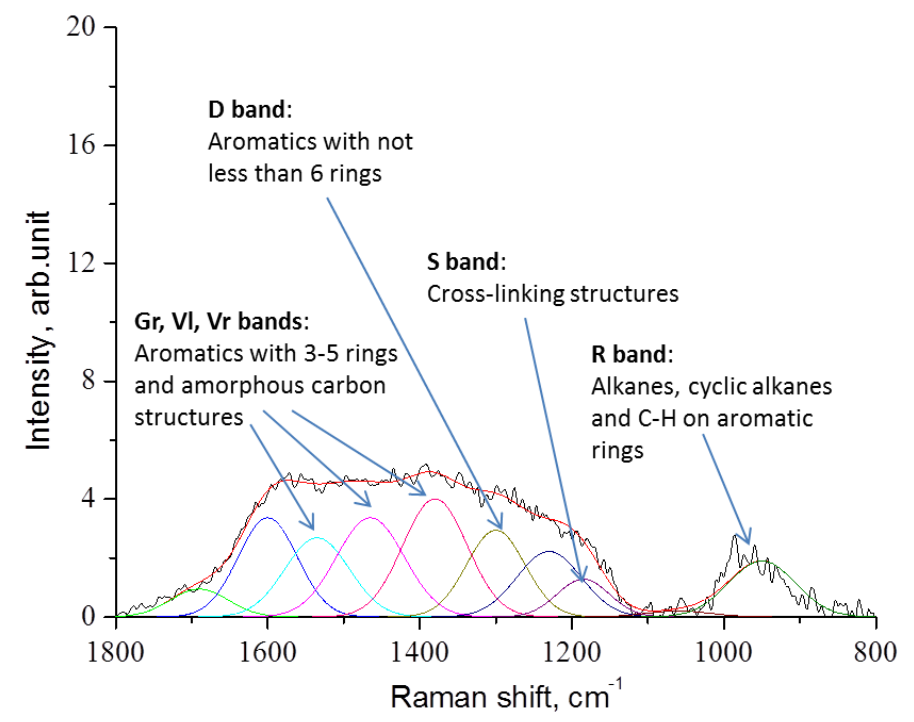

Fig. 1. Deconvolution of a Raman spectrum of Loy Yang char pyrolysed at $600{ }^{\circ} \mathrm{C}$ with $0 \mathrm{~s}$ holding. (Redrawn using new data based on that in [12], Copyright (2006), with permission from Elsevier). 


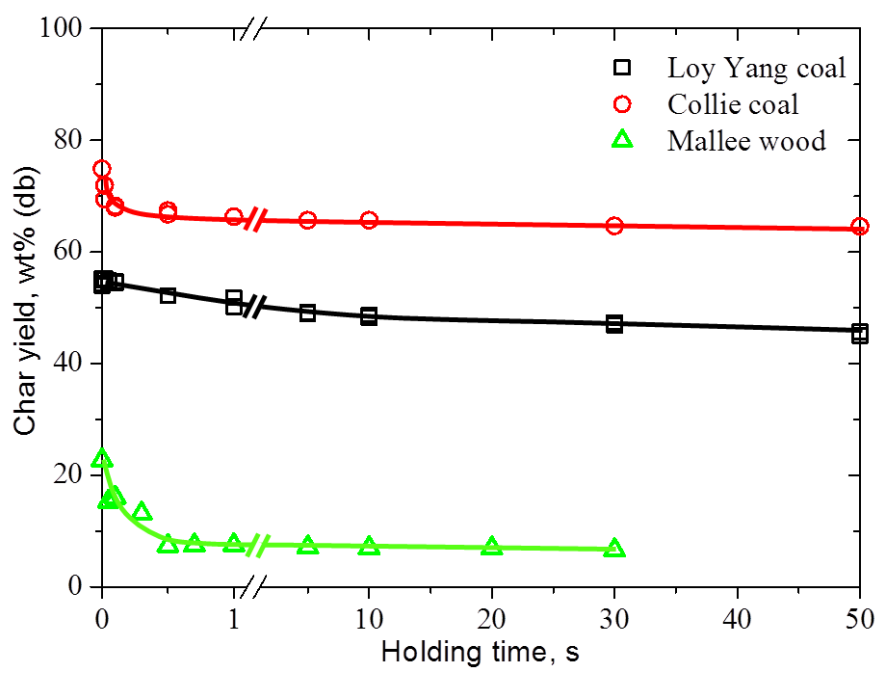

Fig. 2 Char yields of three fuels as a function of holding time at $600{ }^{\circ} \mathrm{C}$. 

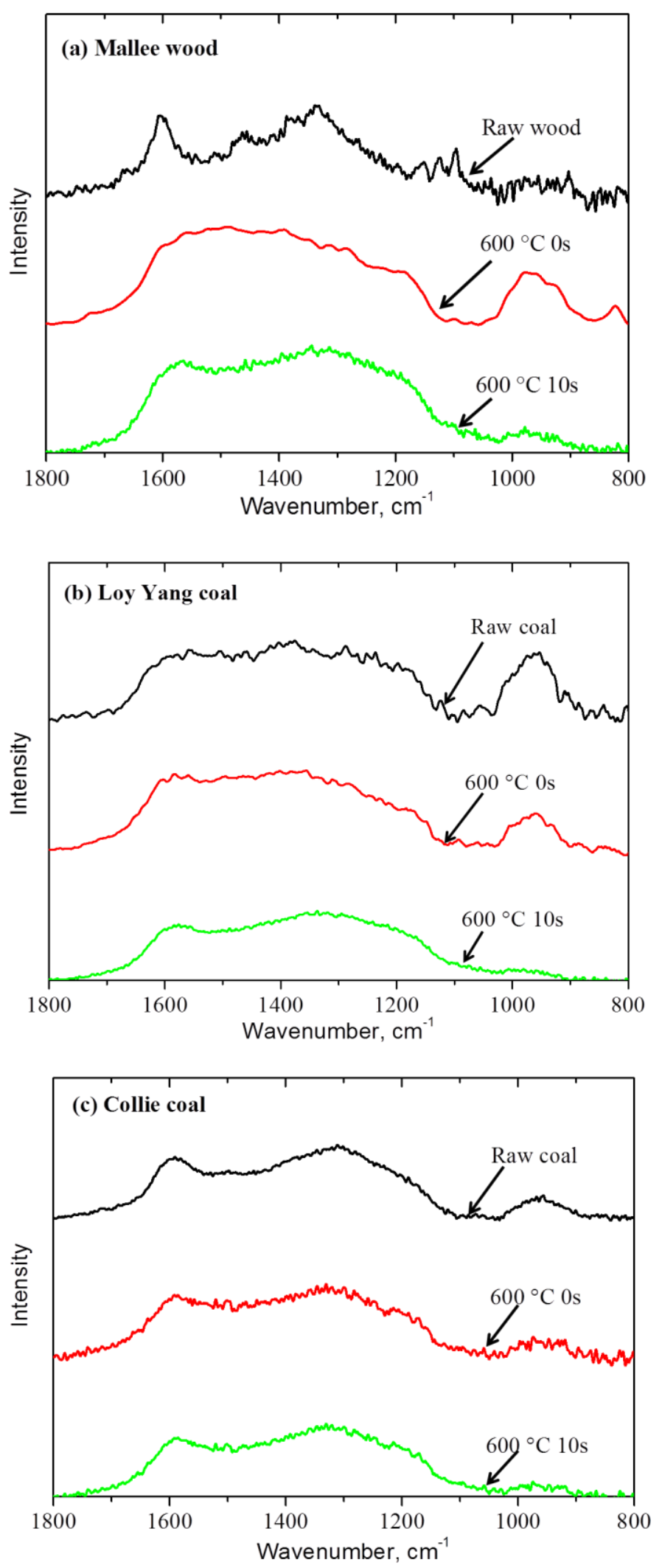

Fig. 3 Raman spectra of three fuels and their nascent chars. 

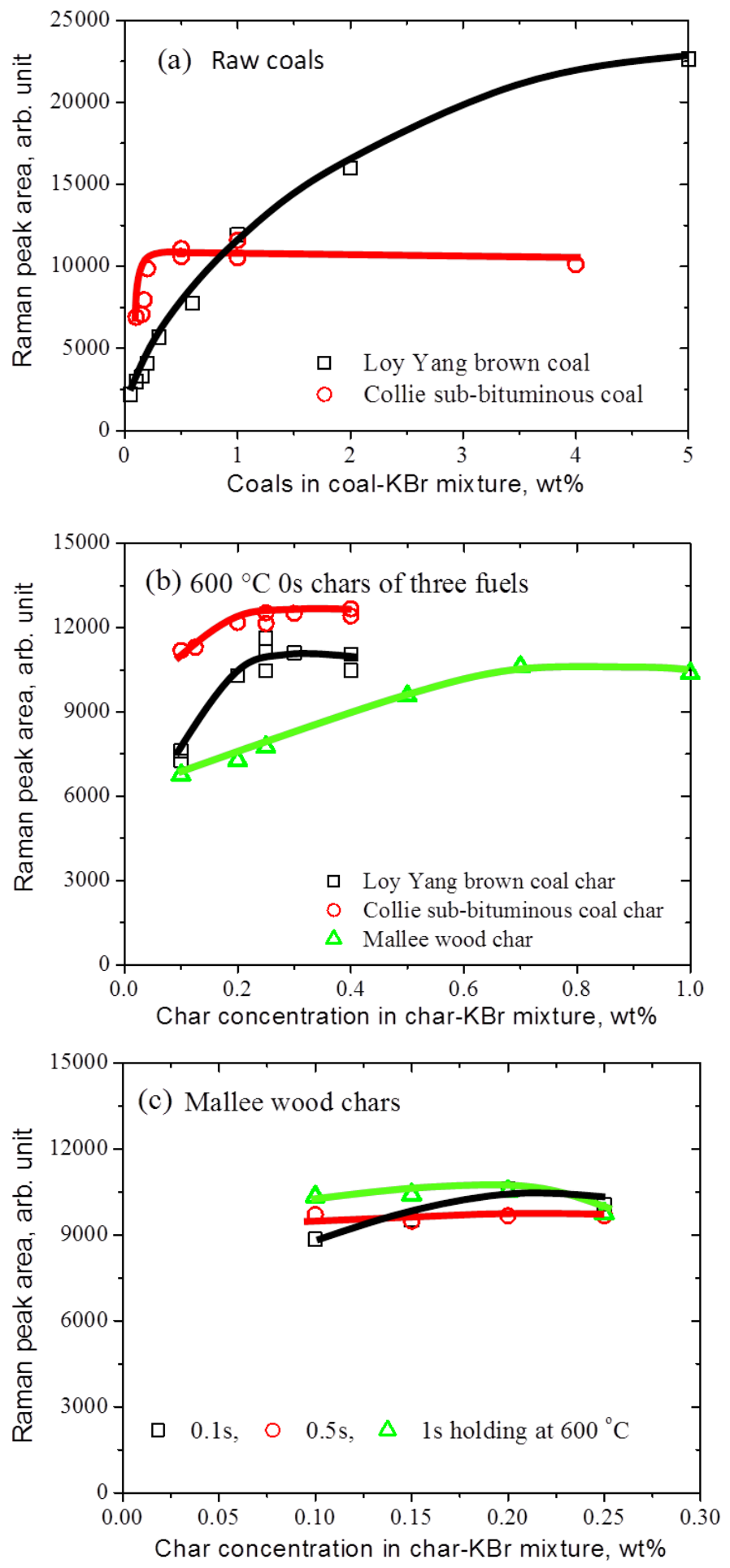

Fig. 4. Total Raman areas of coal/char as a function of the concentration of coal/char in coal/char-KBr mixture. 


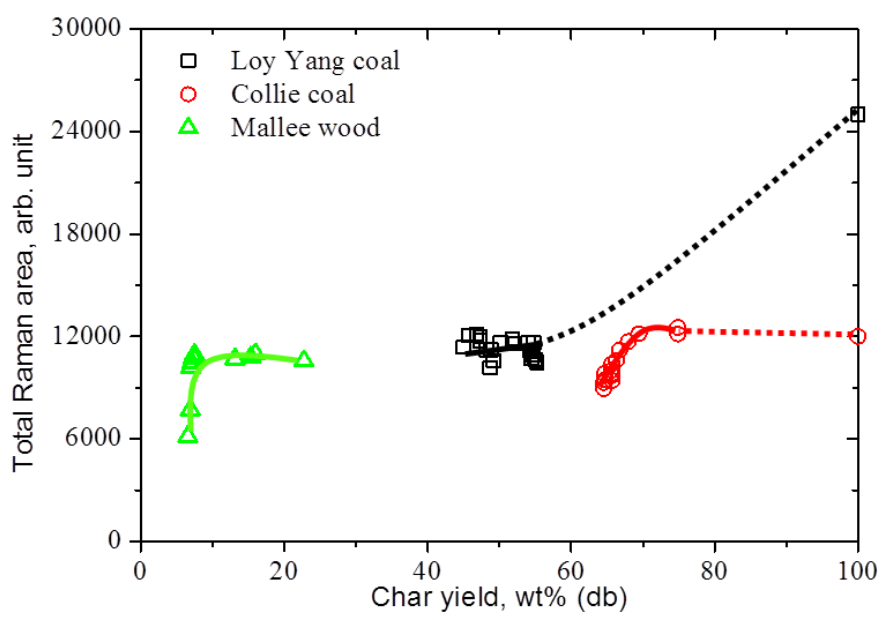

Fig. 5 Total Raman areas of raw fuels and their chars produced by pyrolysis at $600{ }^{\circ} \mathrm{C}$, as a function of char yield. The residence time of Mallee wood was 0-30 s and two coals was $0-$ $50 \mathrm{~s}$ at $600{ }^{\circ} \mathrm{C}$. 


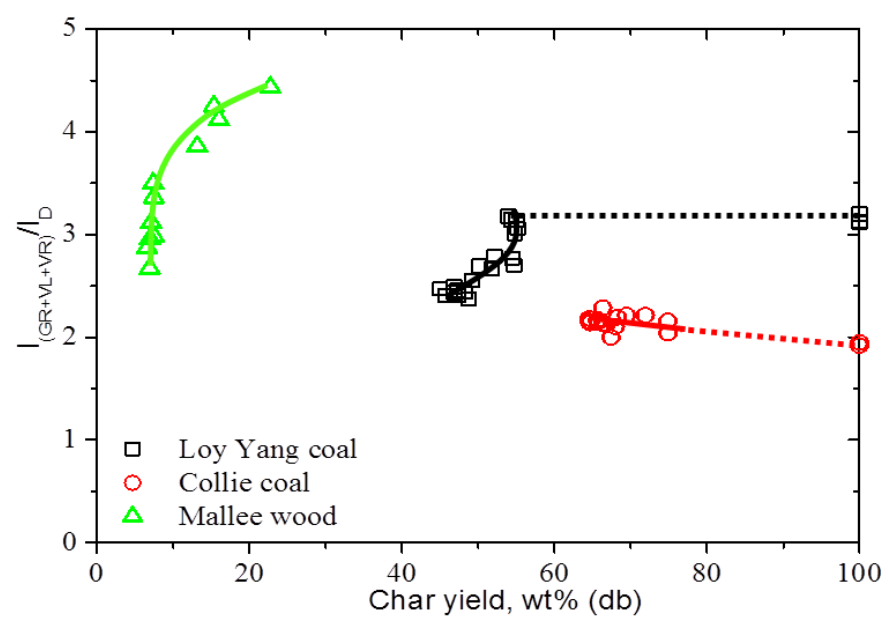

Fig. $6 \mathrm{I}_{(\mathrm{GR}+\mathrm{VL}+\mathrm{VR})} / \mathrm{I}_{\mathrm{D}}$ of raw fuels and their chars produced by pyrolysis at $600{ }^{\circ} \mathrm{C}$, as a function of char yield. The residence time of Mallee wood was 0-30s and two coals was 0-50 s at $600{ }^{\circ} \mathrm{C}$. 


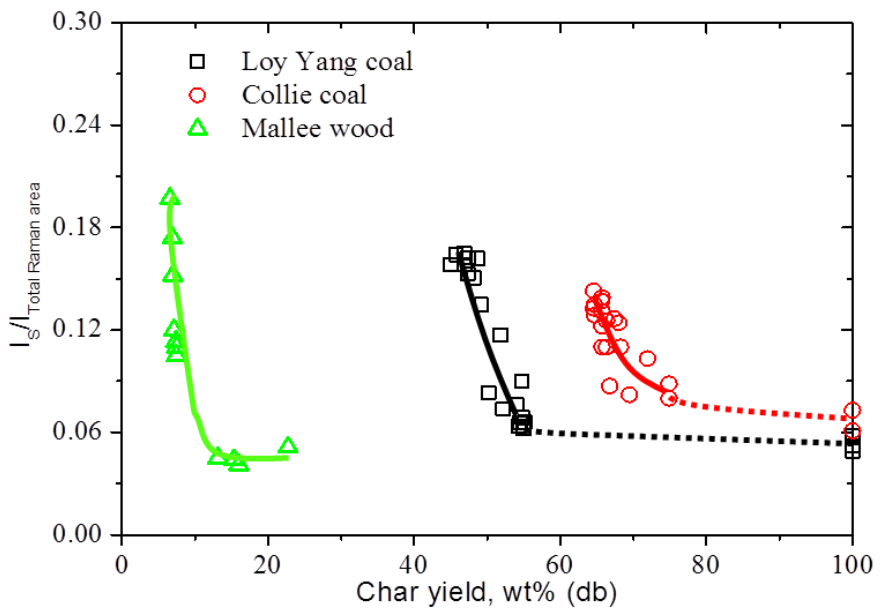

Fig. $7 \mathrm{I}_{\mathrm{S}} / \mathrm{I}_{\text {Total Raman area }}$ of raw fuels and their chars produced by pyrolysis at $600{ }^{\circ} \mathrm{C}$, as a function of char yield. The residence time of Mallee wood was 0-30s and two coals was $0-$ $50 \mathrm{~s}$ at $600{ }^{\circ} \mathrm{C}$. 


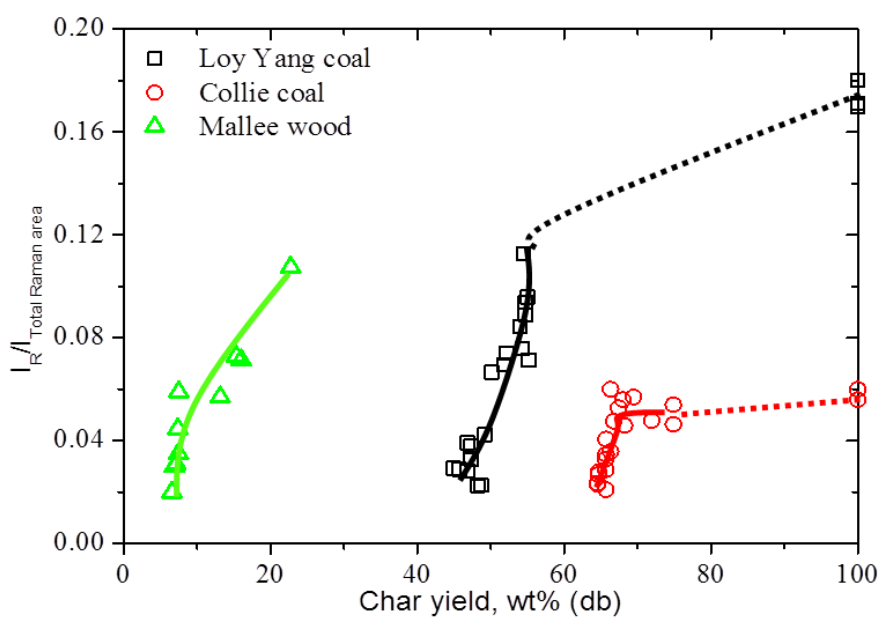

Fig. $8 \mathrm{I}_{\mathrm{R}} / \mathrm{I}_{\text {Total Raman area }}$ of raw fuels and their chars produced by pyrolysis at $600{ }^{\circ} \mathrm{C}$, as a function of char yield. The residence time of Mallee wood was 0-30s and two coals was 0$50 \mathrm{~s}$ at $600{ }^{\circ} \mathrm{C}$. 
- This study aims to trace the structural changes from coal/biomass to nascent char during pyrolysis.

- Heating coal rapidly to $600^{\circ} \mathrm{C}$ causes insignificant changes to the aromatic rings and crosslinks.

- Sub-bituminous coal behaves very differently from brown coal and wood during initial pyrolysis. 